\title{
lonic Mechanisms Underlying the Positive Chronotropy Induced by $\beta 1$-Adrenergic Stimulation in Guinea Pig Sinoatrial Node Cells: a Simulation Study
}

\author{
Yukiko HIMENO ${ }^{1}$, Nobuaki SARAI ${ }^{2}$, Satoshi MATSUOKA ${ }^{1}$, and Akinori NOMA ${ }^{1}$ \\ ${ }^{1}$ Department of Physiology and Biophysics, Graduate School of Medicine, and ${ }^{2}$ Nano-Medicine Merger Education Unit, Kyoto \\ University, Yoshida-Konoe, Sakyo-ku, Kyoto 606-8501, Japan
}

\begin{abstract}
Positive chronotropy induced by $\beta 1$-adrenergic stimulation is achieved by multiple interactions of ion channels and transporters in sinoatrial node pacemaker cells (SANs). To investigate the ionic mechanisms, we updated our SAN model developed in 2003 and incorporated the $\beta 1$-adrenergic signaling cascade developed by Kuzumoto et al. (2007). Since the slow component of the delayed rectifier $\mathrm{K}^{+}$current $\left(I_{K S}\right)$ is one of the major targets of the $\beta 1$-adrenergic cascade, we developed a guinea pig model with a large $I_{K S^{s}}$. The new model provided a good representation of the experimental characteristics of SANs. A comparison of individual current during diastole recorded before and after $\beta 1$-adrenergic stimulation clearly showed the negative shift of the L-type $\mathrm{Ca}^{2+}$ current $\left(I_{\mathrm{CaL}}\right)$ takeoff potential, enlargement of the sustained inward current $\left(I_{s t}\right)$, and the hy-
\end{abstract}

perpolarization-activated nonselective cation current $\left(I_{\text {ha }}\right)$ played major roles in increasing the firing frequency. Deactivation of $I_{K s}$ during diastole scarcely contributed to the time-dependent decrease in membrane $\mathrm{K}^{+}$conductance, which was the major mechanism for slow diastolic depolarization, as indicated by calculating the instantaneous equilibrium potential (lead potential). This was because the activation of $I_{K S}$ during the preceding action potential was negligibly small. However, $I_{K s}$ was important in counterbalancing the increase in $I_{\mathrm{CaL}}$ and the $\mathrm{Na}^{+} / \mathrm{Ca}^{2+}$ exchange current $\left(I_{\mathrm{NaCa}}\right)$, which otherwise compromised the positive chronotropic effect by elongating the action potential duration. Enhanced $\mathrm{Ca}^{2+}$ release from the sarcoplasmic reticulum failed to induce an obvious chronotropic effect in our model.

Key words: $\beta 1$-adrenergic receptor, cardiac pacemaker model, sinoatrial node, sympathetic nerve stimulation, simulation.

Sympr (SANs) is essential for increasing heart rate when a larger blood supply is required for the body. The autonomic neurotransmitter, noradrenaline, is released from nerve terminals, binds to the $\beta 1$-adrenergic receptor, and initiates intracellular signal transduction in SANs, which causes the increased firing frequency of spontaneous action potentials. This positive chronotropy is due to a variety of functional modifications of ion channels and ion transporters. To date, electrophysiological and pharmacological studies have provided experimental evidence to show that ion channels and transporters are modified by the $\beta 1$-adrenergic stimulation. To clarify the contributions of each current, however, an integrative analysis is required because positive chronotropy is induced by multiple interactions of all ion channels and transporters, which have different kinetics and respond differently to $\beta 1$-adrenergic stimulation. In 2003, we developed a SAN model that included spontaneous action potential generation and intracellular ion homeostasis, including $\mathrm{Ca}^{2+}$ dynamics [1, 2]. Using this model, we proposed the principal ionic mechanisms underlying the spontaneous action potential. In the current study, we revised the model by updating the ion channels and incorporating the mitochondria and $\beta 1$-adrenergic cascade models described by Matsuoka et al. (2004), Terashima et al. (2006), Takeuchi et al. (2006), and Kuzumoto et al. (2007) [3-6] to analyze the roles of each target ion current, including the L-type $\mathrm{Ca}^{2+}$ current $\left(I_{C a L}\right)$, the sustained inward current $\left(I_{s t}\right)$, the hyperpolarizationactivated cation current $\left(I_{h a}\right)$, and the slow component of the delayed rectifier $\mathrm{K}^{+}$current $\left(I_{K s}\right)$ in the positive chronotropy during $\beta 1$-adrenergic stimulation. Our new model also includes an alteration of $\mathrm{Ca}^{2+}$ dynamics during stimulation by calculating a modification of the $\mathrm{Ca}^{2+}$ pump (SERCA) on the sarcoplasmic membrane. Thus we discuss the hypothesis that $\mathrm{Ca}^{2+}$ release from the sarcoplasmic reticulum (SR) plays a crucial role in regulating pacemaker activity [7-10].

Received on Dec 25, 2007; accepted on Jan 16, 2008; released online on Jan 19, 2008; doi:10.2170/physiolsci.RP015207 Correspondence should be addressed to: Akinori Noma, Department of Physiology and Biophysics, Graduate School of Medicine, Kyoto University, Yoshida-Konoe, Sakyo-ku, Kyoto 606-8501, Japan. Tel: +81-75-753-4357, Fax: +81-75-753-4349, E-mail: noma@card.med.kyoto-u.ac.jp 
It is well established that the decay in $\mathrm{K}^{+}$conductance during slow diastolic depolarization is crucial for the generation of spontaneous action potentials [11, 12], and this $\mathrm{K}^{+}$conductance is mainly supported by the rapid component of the delayed rectifier $\mathrm{K}^{+}$current $\left(I_{K r}\right)$ in rabbit. However, Matsuura et al. (2002) [13] demonstrated that the guinea pig SANs show a significant amplitude of $I_{K s}$ during the depolarizing pulse, and also $I_{K s}$ tail on repolarization, which was not the case in rabbit SANs (see also Anumonwo et al. (1992) [14]). Furthermore, $I_{K s}$ is one of the major targets of the $\beta 1$-adrenergic cascade. Therefore in this study we examined if $I_{K s}$ in guinea pig could be substituted for $I_{K r}$ in contributing to pacemaker depolarization during $\beta 1$-adrenergic chronotropy. We constructed a guinea pig SAN model with reference to the experimental data for $I_{K r}$ and $I_{K s}$ obtained from guinea pig SANs by Matsuura et al. [13]. As far as we know, this is the first attempt to investigate the mechanism of the positive chronotropy of firing rate in a SAN model including intracellular $\beta 1$-adrenergic signaling cascades.

\section{MATERIALS AND METHODS}

Parameter set in the guinea pig SAN model. The extracellular ion concentrations (in $\mathrm{mM}$ ) were 141 for $\mathrm{Na}^{+}, 5.4$ for $\mathrm{K}^{+}, 1.8$ for $\mathrm{Ca}^{2+}, 140$ for $\mathrm{Cl}^{-}$, and 10 for large anionic compounds (LA). LA was membrane-impermeable. A schematic diagram of the SAN model is shown in Fig. 1. General abbreviations are listed in the Table S1, the equations describing the kinetic behavior of individual functional units are in Tables S2-15, and steady state variables such as ionic currents, flux, and metabolite concentrations are given in Table S16 in the online supplemental material. The basic structure of the guinea pig model is the same as that of the SAN model based mainly on rabbit data [2]. Assuming that the membrane potential $\left(V_{m}\right)$ is homogeneous within a single cell, we calculated $d V_{m} / d t$ from the total current of ion channels and ion exchangers $\left(I_{t o t}\right)$ normalized for the input membrane capacitance $\left(C_{m}\right)$ and the current applied through the electrode $\left(I_{\text {ext }}\right)$ as follows (see also Table S4),

$$
\begin{gathered}
d V_{m} / d t=-\left(I_{t o t}+I_{e x t}\right) \\
I_{t o t}=I_{N a}+I_{C a L}+I_{C a T}+I_{s t}+I_{h a}+I_{K l}+I_{K r}+I_{K s}+ \\
I_{K A C h}+I_{l}+I_{N a C a}+I_{N a K}+I_{P M C A}
\end{gathered}
$$

See Tables S7, S8, S9, and S11 for definitions and equations for each current. The total background current $\left(I_{l}\right)$ is defined as

$$
I_{l}=I_{b N S C}+I_{C a b}+I_{K p l}+I_{l(C a)}+I_{K A T P}+I_{C l b}
$$

See Table S10 for definitions and equations for each background current. The following functions were newly added to the model. First, ATP production by oxidative phosphorylation, creatine kinase, and adenylate kinase [3, 15] (Tables S5 and S15) was implemented. The ATP production rate was adjusted to obtain a steady state [ATP] of $7.0 \mathrm{mM}$, which was in the range of 5-10 mM [16]. A ratio $[\mathrm{NADH}] /([\mathrm{NAD}]+[\mathrm{NADH}])=0.29$ was within the range of values obtained experimentally in guinea pig ventricular myocytes [17]. Second, the mechanisms of $\mathrm{Cl}^{-}$homeostasis and volume regulation $[4,5]$ were incorporated by including ion flux via a $\mathrm{Na}^{+} / \mathrm{K}^{+} / 2 \mathrm{Cl}^{-}$cotransporter 1 $\left(J_{N K C C l}\right)$, background $\mathrm{Cl}^{-}$current $\left(I_{C l b}\right)$, water flux, and LA. The magnitudes of $I_{C l b}$ and water flux were scaled according to the ratio of input capacitance between SANs and ventricular cells (Tables S4 and S9). The intracellular $\mathrm{Cl}^{-}$concentration was set at about $30 \mathrm{mM}$ by adjusting the activity of $J_{N K C C l}$. Since the cystic fibrosis transmembrane conductance regulator (CFTR) $\mathrm{Cl}^{-}$channel current $\left(I_{C F T R}\right)$ was reported to be absent [18] and no data were available for $I_{V R C C}$ in SANs, they were not included in our model. Equations for the protein kinase A (PKA) and the cAMP effect on $I_{s t}$ and $I_{h a}$ were newly implemented in the

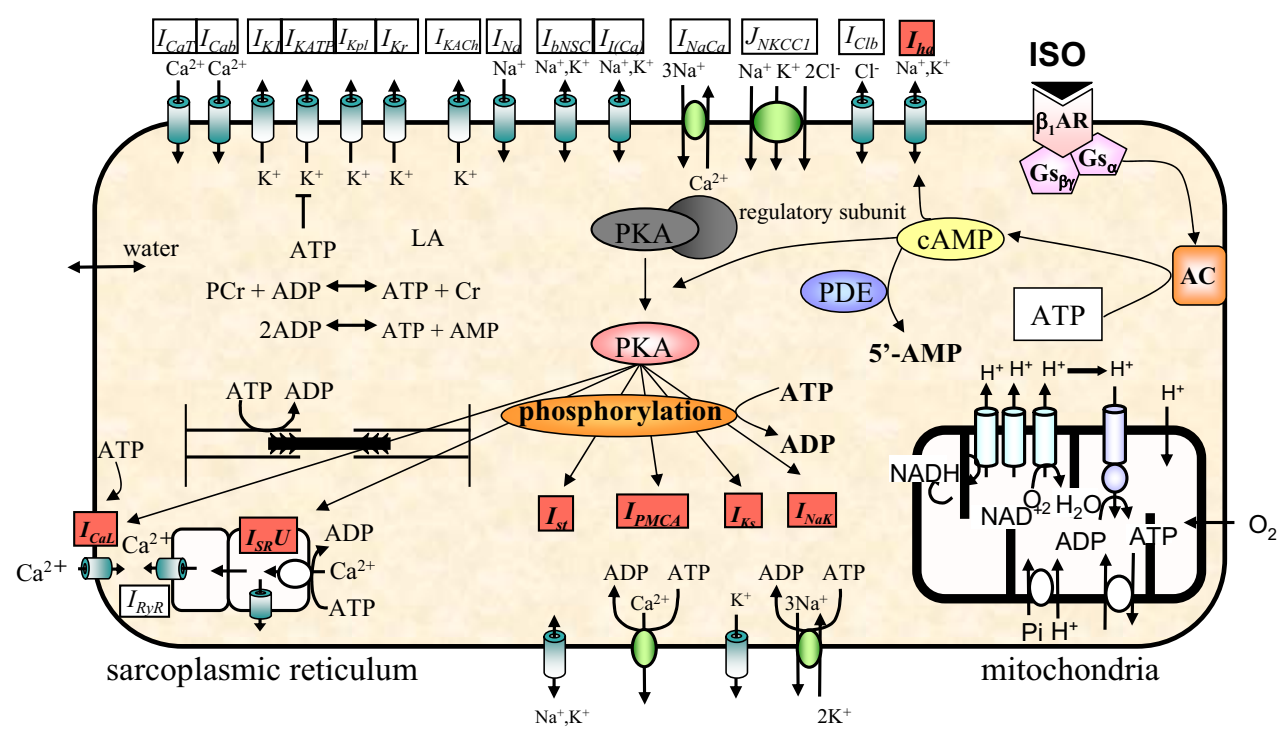

Fig. 1. Schematic diagram of the guinea pig SA node cell model. 
A
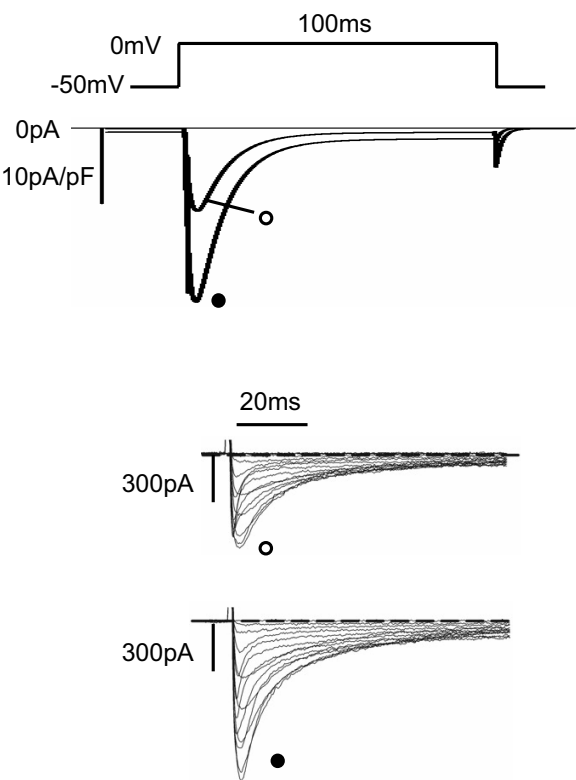

B
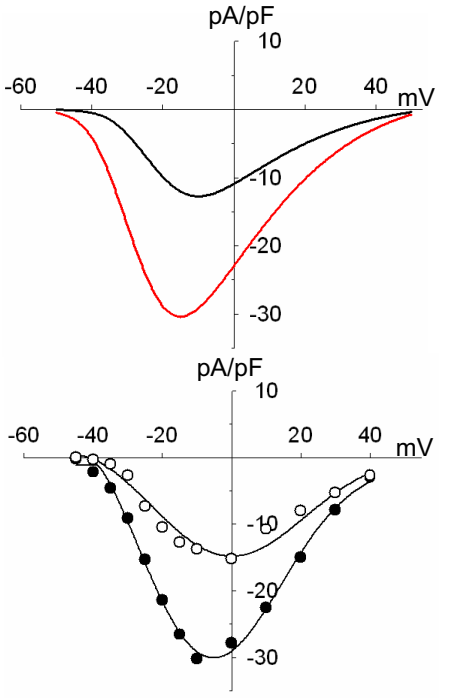

C

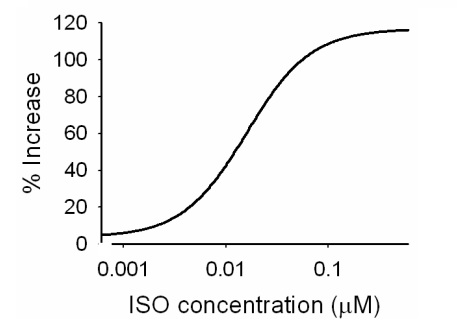

Fig. 2. Comparison of $I_{C a L}$ between simulation and experiment. (A) The upper panel shows the reconstructed $I_{\mathrm{CaL}}$ with a test pulse to $0 \mathrm{mV}$ from a holding potential of $-50 \mathrm{mV}$ under control conditions $(\mathrm{O})$ and with $0.1 \mu \mathrm{M}$ ISO $(\bullet)$, and the lower panel shows corresponding experimental data with test pulses from -40 to $+50 \mathrm{mV}$ [24]. (B) Simulated peak $\mathrm{I}-\mathrm{V}$ relationships of $I_{\mathrm{CaL}}$ with (red line) and without (black line) $0.1 \mu \mathrm{M}$ ISO are compared with experimental I-V relationships [24] in the lower panel (with [0] and without [O] $0.1 \mu \mathrm{M}$ ISO). (C) Simulated concentrationresponse relationship $\left(n_{H}=-1.39\right.$, $\left.\mathrm{K}_{\mathrm{D}}=0.0158 \mu \mathrm{M}\right)$ for the enhancement of $I_{C a L}$ by ISO measured with a test pulse to $0 \mathrm{mV}$ from a holding potential of $-50 \mathrm{mV}$.
SAN model. And third, the $\beta 1$-adrenergic signaling module [6] (Tables S6 and S12) was incorporated in the model. Target proteins of $\beta 1$-adrenergic signaling, including $I_{K s}$, are colored in red in the diagram (Fig. 1). One significant feature of guinea pig SANs is a larger $I_{K s}$, compared to $I_{K r}$ as indicated by Anumonwo et al. (1991) [14] and Matsuura et al. (2002) [13], in contrast to rabbit SANs, which has an almost negligible $I_{K s}$ [19]. In regard to the kinetic equations for $I_{K r}$, we adopted those developed for $I_{K r}$ in rabbit by Ono and Ito (1995) [20].

Ordinary differential equations were integrated using the Euler method with an adaptive time step, and simultaneous equations were solved by Broyden's method, a quasi-Newton procedure. The model was constructed with a Java-based simulation platform, simBio [21]. The source code is available at http://www.sim-bio.org/.

lonic channels and transporters modulated in the $\beta 1$ adrenergic signaling cascade model. In our SAN model, $I_{C a L}, I_{s t}, I_{h a}, I_{K s}, I_{N a K}$, the plasma membrane $\mathrm{Ca}^{2+}$-ATPase (PMCA) current $\left(I_{P M C A}\right)$ and the SR $\mathrm{Ca}^{2+}$ pump (SERCA) current $\left(I_{S R} U\right)$, are enhanced by $\beta 1$-adrenergic stimulation. Such stimulation activates adenylate cyclase via Gprotein $\left(\mathrm{G}_{\mathrm{s}}\right)$ and elevates the cAMP level. The increased cAMP activates PKA by unleashing its catalytic subunits to phosphorylate the above target proteins, except for $I_{h a}$, which is directly modulated by the concentration of cAMP. In the simulation, the activities of $I_{C a L}, I_{s t} I_{h a}, I_{K s}$, $I_{N a K}, I_{P M C A}$ and SERCA $\left(I_{S R} U\right)$ were modulated as a function of the concentration of PKA catalytic subunits or cAMP, as follows.
(1) $I_{C a L}$ : Equations for $I_{C a L}$ were basically the same as those used in the ventricular cell model [6]. The increase of $I_{C a L}$ and negative shift of current-voltage (I-V) relationships by $\beta 1$-adrenoceptor stimulation were reconstructed by defining model equations as functions of [PKA], the concentration of free catalytic subunit of PKA. The fully activated amplitude of $I_{C a L}$ was multiplied by $f_{P K A}$, which is given as (Table S7),

$$
\begin{aligned}
f_{P K A}= & \max \cdot([\mathrm{PKA}]-\mathrm{PKA} 0)^{\mathrm{nH}} /\left\{([\mathrm{PKA}]-\mathrm{PKA} 0)^{\mathrm{nH}}\right. \\
& \left.+\mathrm{K}_{\mathrm{m}} \mathrm{PKA}^{\mathrm{nH}}\right\}+1
\end{aligned}
$$

where the value for the concentration of PKA in the absence of $\beta 1$-adrenergic stimulation (PKA0 $=0.000136$ $\mathrm{mM}$ ) was obtained from the original paper by Kameyama et al. (1985) [22] and other values for the maximum amplitude (max), Hill coefficient $(\mathrm{nH})$ and the equilibrium constant for PKA ( $\left.\mathrm{K}_{\mathrm{m}} \mathrm{PKA}\right)$ were determined to reconstruct the recorded increase of $I_{C a L}$ by ISO described by Zaza et al. (1996) [23] and Ke et al. (2007) [24] in SANs (17.5, 1 and $0.0065 \mathrm{mM}$, respectively).

The voltage shift of gating was given by biasing $V_{m}$ with the following $V_{\text {shift }}$ in all equations defining the rate constants of the voltage-dependent gate (Table S7):

$$
\begin{aligned}
V_{\text {shift }}= & 62.5 \cdot([\mathrm{PKA}]-\mathrm{PKA} 0)^{\mathrm{nH} /}\left\{([\mathrm{PKA}]-\mathrm{PKA} 0)^{\mathrm{nH}}\right. \\
& \left.+\mathrm{K}_{\mathrm{m}} \mathrm{PKA}^{\mathrm{nH}}\right\}
\end{aligned}
$$

Parameters for $\mathrm{Ca}^{2+}$-dependent inactivation gate were adjusted to obtain the experimental inactivation time course of $I_{C a L}$, as shown in Fig. 2A [24]. In both simulation and 
A
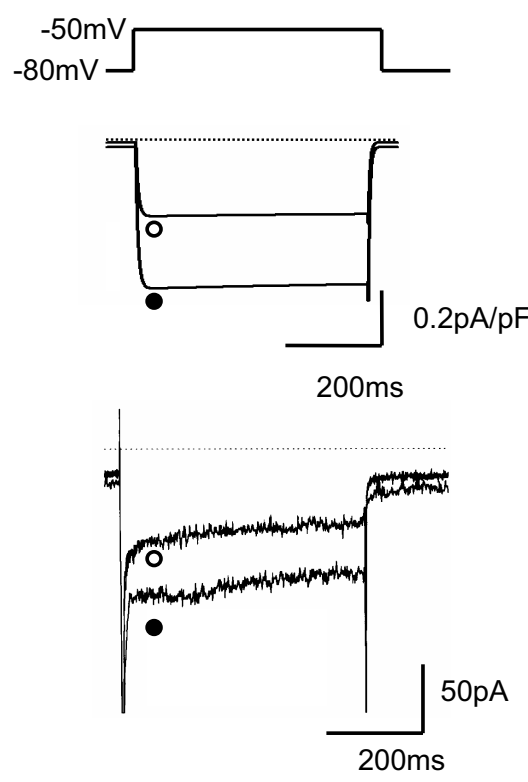

B

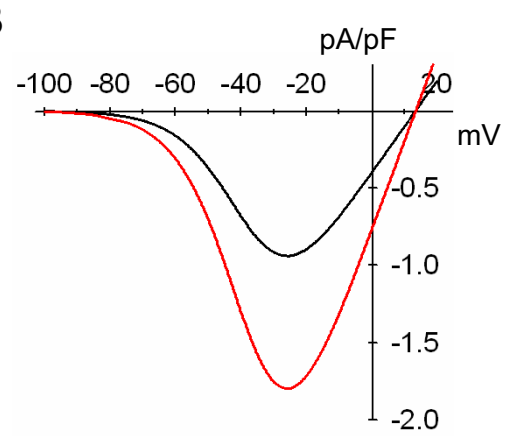

C

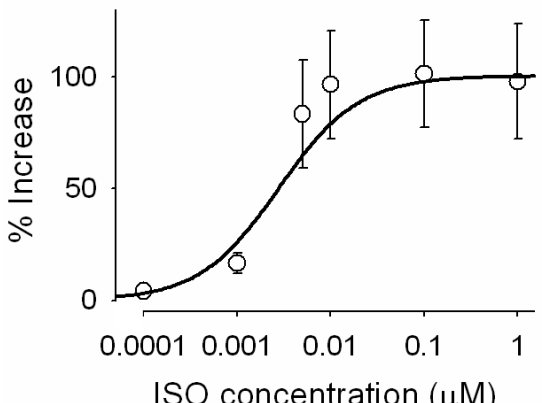

Fig. 3. Comparison of $I_{s t}$ (A) Voltage clamp records of $I_{s t}$ with $(\bullet)$ and without $(\mathrm{O}) 0.1 \mu \mathrm{M}$ ISO in simulations (upper panel) and experiments [30] (lower panel). (B) Simulated peak I-V relationships of $l_{s t}$ with (red line) and without (black line) $0.1 \mu \mathrm{M}$ ISO. The holding potential was $-80 \mathrm{mV}$. (C) ISO concentration- ${ }_{s t}$ relationship compared to experimental data (mean \pm SEM) [26]. experiment, the amplitudes were approximately doubled by adding $0.1 \mu \mathrm{M}$ isoprenaline (ISO). The negative shift of the peak I-V relationship was approximately $7 \mathrm{mV}$ (Fig. 2B, upper panel), as obtained experimentally in guinea-pig SANs (Fig. 2B, lower panel) [24] and in various types of cells [25]. In the dose-response curve in Fig. $2 \mathrm{C}$, saturated increase of $I_{C a L}$ was $116 \%$ of the control.

(2) $I_{s t}$ : The increase of $I_{s t}$ was reconstructed by defining the limiting amplitude as a function of [PKA] (Table S7). The fully activated amplitude of $I_{s t}$ was multiplied by $f_{P K A}$, which is given by the same equation for $I_{C a L}$ (Eq. 4), but values for max and $\mathrm{K}_{\mathrm{m}}$ PKA were different from those of $I_{\text {CaL }}$ (1.0 and $0.000065 \mathrm{mM}$, respectively). In Fig. 3, cur- rents in the presence of $0.1 \mu \mathrm{M}$ ISO (-) were approximately doubled compared to the control $(O)$ in both the simulation and the experiment. The I-V relationships in Fig. 3B were reconstructed with and without ISO by plotting the amplitude of the initial peak $I_{s t}$ measured at the beginning of depolarizing pulses. The reversal potential of $I_{s t}$ was $+12 \mathrm{mV}$. The amplitudes of the current were increased in a dose-dependent manner as shown in Fig. 3C, in agreement with the experimental data of Toyoda et al. (2006) [26].

(3) $I_{h a}:$ The positive shift in voltage-dependent activation of $I_{h a}$ was defined as a function of the concentration of free cAMP, [cAMP] (Table S7). As for $I_{C a L}$, the voltage
A
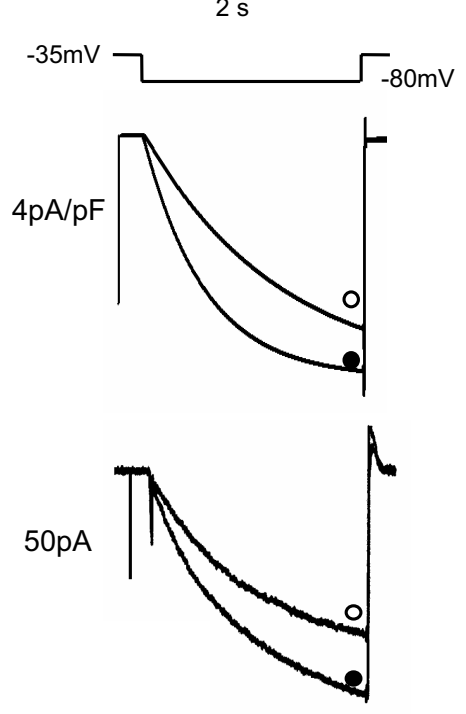

B
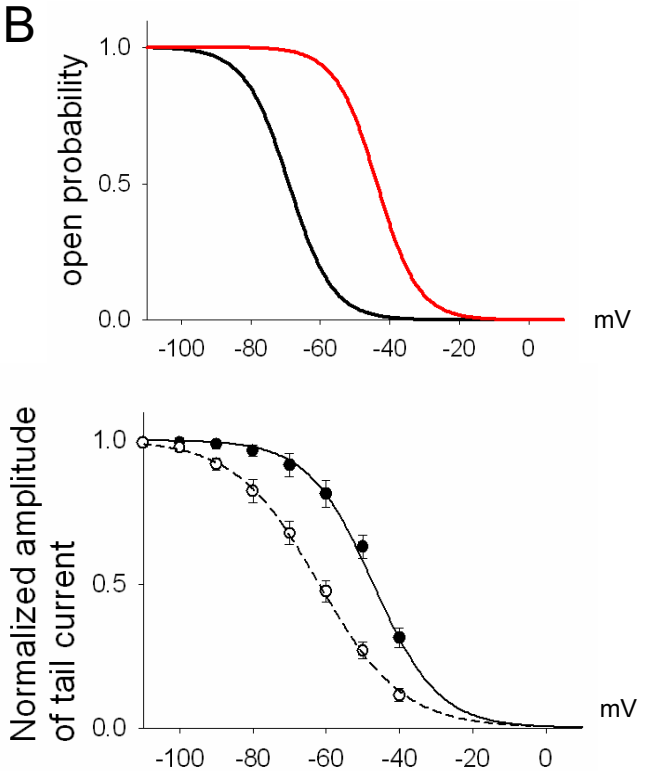

Fig. 4. Comparison of $I_{h a}$ (A) Voltage clamp records of $I_{\text {ha }}$ with (๑) and without (O) ISO in simulations (upper panel) and experiments [27] (lower panel). ISO concentrations were $0.1 \mu \mathrm{M}$ in the simulation and $1 \mu \mathrm{M}$ experimentally. Traces were elicited by $2 \mathrm{~s}$ test pulses to $-80 \mathrm{mV}$ from a holding potential of $-35 \mathrm{mV}$. (B) Simulated activation-voltage relationships of $I_{h a}$ with (red line) and without (black line) $1 \mu \mathrm{M}$ ISO are compared with experimental I-V relationships in the lower panel (with [0] and without [O] $1 \mu \mathrm{M}$ ISO) [28]. Data were obtained at the end of $4 \mathrm{~s}$ hyperpolarizing pulses to various test potentials from a holding potential of -40 $\mathrm{mV}$. 
A
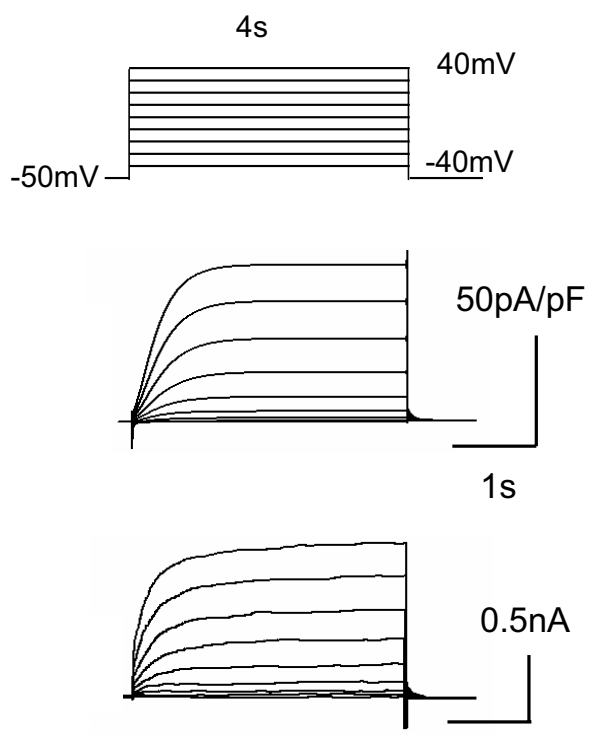

1s
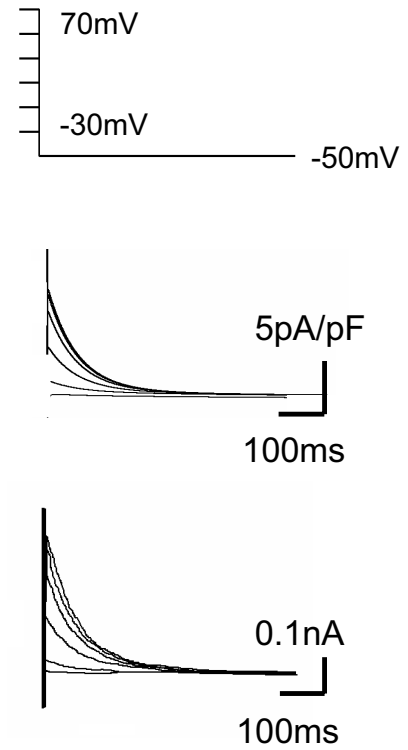

B
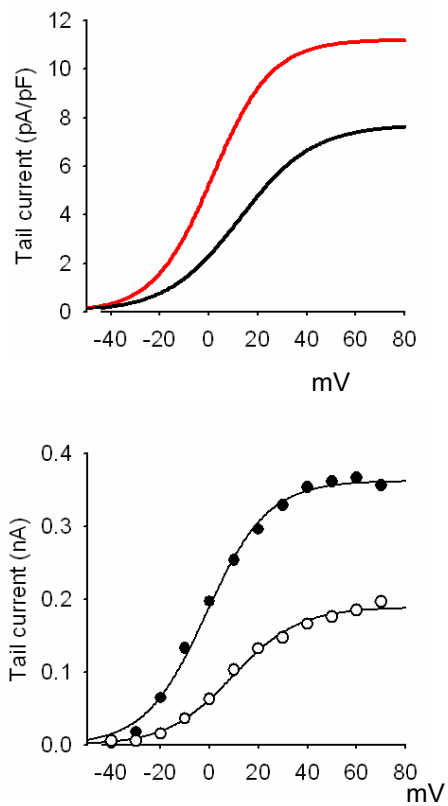

Fig. 5. Comparison of $I_{K s}$. (A) Current traces during $4 \mathrm{~s}$ voltage clamp steps to membrane potentials in the range -40 to +40 $\mathrm{mV}$ from a holding potential of $-50 \mathrm{mV}$ and expanded tail currents elicited after depolarizing steps to $-30,-10,+10,+30$, +50 , and $+70 \mathrm{mV}$ in simulation (upper panel) and in experiments by Matsuura et al. (2002) (lower panel) [13]. $I_{K r}$ was blocked in the simulation and was blocked with $5 \mu \mathrm{M}$ E-4031 in the experiment. The tail current was fitted by a sum of two ex- ponential functions with time constants of $\tau_{\mathrm{f}}=61.0 \mathrm{~ms}$ and $\tau_{\mathrm{s}}=$ $122.7 \mathrm{~ms}$ at $-50 \mathrm{mV}$, compared to 44.4 and $151.5 \mathrm{~ms}$ in the experiment. (B) I-V relationships for $I_{K s}$ tail currents obtained with (red line) and without (black line) application of $1.0 \mu \mathrm{M}$ ISO are compared with experimental I-V relationships [29] in the lower panel (with [0] and without [O] $1 \mu \mathrm{M}$ ISO). Data points were obtained at the end of $4 \mathrm{~s}$ depolarizing pulses to various test potentials from a holding potential of $-50 \mathrm{mV}$. shift of gating was given by biasing $V_{m}$ with $V_{\text {shift }}$ (calculated as follows) in all equations defining the rate constants of the voltage dependent gate,

$$
\begin{aligned}
V_{\text {shift }}= & 15 \cdot([\mathrm{cAMP}]-\mathrm{cAMP} 0)^{\mathrm{nH}} /\{([\mathrm{cAMP}]- \\
& \left.\mathrm{cAMP0})^{\mathrm{nH}}+\mathrm{K}_{\mathrm{m}} \mathrm{cAMP}{ }^{\mathrm{nH}}\right\}
\end{aligned}
$$

where values for the concentration of cAMP in the absence of $\beta 1$-adrenergic stimulation (cAMP0), $\mathrm{nH}$ and the equilibrium constant for cAMP $\left(\mathrm{K}_{\mathrm{m}} \mathrm{cAMP}\right)$ were $0.000294 \mathrm{mM}, 1$ and $0.0002 \mathrm{mM}$, respectively. [cAMP] represents the concentration of free cAMP. In Fig. 4A, $I_{h a}$ activated at $-80 \mathrm{mV}$ in the presence of $0.1 \mu \mathrm{M}$ ISO $\left([\mathrm{cAMP}]_{\mathrm{i}}=4.88 \mu \mathrm{M}\right)$ was larger than the control, as in experiments [27] shown in the lower panel. The simulated activation time course of $I_{h a}$ in the presence of ISO was accelerated slightly. The voltage-shift of activation in the simulation was similar to that in the experimental data, as shown in Fig. 4B [28]. The $\mathrm{V}_{1 / 2}$ of the sigmoid curves obtained in the control and in the presence of $1 \mu \mathrm{M}$ ISO were $-69.1 \mathrm{mV}$ and $-43.7 \mathrm{mV}$, respectively, in the simulation (upper panel) and $-61.9 \mathrm{mV}$ and $-47.1 \mathrm{mV}$, respectively, in experiments (lower panel). It should be noted that $I_{h a}$ could be activated over the voltage range of slow diastolic depolarization in the presence of $\beta 1$-adrenergic stimulation.

(4) $I_{K s}$ : An $I_{K s}$ model of guinea-pig SANs is a modification of the recently developed new ventricular model [6] (Table S8). Channel gating was described by voltagedependent and $\mathrm{Ca}^{2+}$-dependent activation kinetics, and $\beta 1$-adrenergic stimulation modifies the voltage gate and the current amplitude, as in the ventricular cell model. The voltage dependency and the permeability of the ventricu$\operatorname{lar} I_{K s}$ model was modified according to experimental data obtained by Matsuura et al. (2002) [13]. Figure 5A compares the time courses of $I_{K s}$ activation and deactivation induced by the pulse protocol indicated at the top of the figure. The very slow component of activation was not observed in simulation, but the initial activation time course was similar to those in the experiment. The deactivation time course over the diastolic potential range also agreed with experimental data; it was fitted well by a sum of two exponential components, as in the experiment. The same equations for the PKA effect in the ventricular $\beta 1$-adrenergic signaling model developed by Kuzumoto et al. [6] as shown in Eqs. 7-9 were used in the SAN model. Activated PKA phosphorylated the main subunit of $I_{K s}, \mathrm{KCNQ} 1$ and increased the amplitude of $I_{K s}$ and shifted its voltage-de- 
pendency in a negative direction. The fully activated amplitude of $I_{K s}$ was multiplied by $f_{P K A}$, which is given as a function of a fractional concentration of phosphorylated KCNQ1, F_KCNQ1p,

$$
\begin{aligned}
& F_{-} K C N Q 1 p=[\mathrm{KCNQ} 1 \mathrm{p}] /\left[\mathrm{KCNQ}_{\text {tot }}\right], \\
& f_{P K A}=0.565 /\left\{1+\left(0.4 / F_{-} K C N Q 1 p\right)^{6}\right\}+0.435 .
\end{aligned}
$$

Similarly, the voltage shift was defined by $F_{-} K C N Q 1 p$ as,

$$
V_{\text {shift }}=1.35 \cdot\left\{\left(F_{-} K C N Q 1 p / 0.0947\right)-1\right\} .
$$

In Fig. $5 \mathrm{~B}, I_{K s}$ tail current increased 1.5 - to 2 -fold by 1 $\mu \mathrm{M}$ ISO in the voltage range of action potential, which agreed with experimental data [29].

(5) $I_{N a K}, I_{S R} U$ and $I_{P M C A}$ : Because of insufficient data for $I_{N a K}, I_{S R} U$, and $I_{P M C A}$ in guinea-pig SANs, we used essentially the same equations for kinetics as those in the ventricular cell model [6] (Table S11).

\section{RESULTS}

\section{Whole cell current and current-voltage relationship in the SAN model}

The simulated membrane currents and current-voltage relationships obtained from the guinea pig SAN model (upper panel) are compared with experimental results (lower panel) from Guo et al. (1997) [30] in Fig. 6. Hyperpolarizing pulses from the holding potential of $-50 \mathrm{mV}$ activated the slowly increasing inward current, $I_{h a}$, which became visible from -70 to $-80 \mathrm{mV}$. The activation time courses seemed similar, except for faster activation in the experiment at $-110 \mathrm{mV}$. Depolarizing pulses to various potentials induced transient inward current, which was attributed to $I_{C a L}$, and slowly increased the outward current, $I_{K s}$. The activation threshold of $I_{C a L}$ was $-40 \mathrm{mV}$, and the potential of the peak inward current in the I-V curve was $-10 \mathrm{mV}$ in both the simulation and experiment $(\bullet)$. The voltage range of delayed rectification in the simulation also agreed well with the experimental I-V relationship for the late current (O). On repolarization, outward tail currents were observed as a result of the deactivation of $I_{K s}$ and $I_{K r}$. The contribution of $I_{K r}$ to the tail current was comparable to that of $I_{K s}$; the ratio of $I_{K r} / I_{K s}$ was 0.74 after the depolarizing pulse to $+20 \mathrm{mV}$. This is in contrast to the major contribution of $I_{K S}$ to the onset current during the depolarizing pulse; $I_{K r} / I_{K s}$ was 0.02 during the depolarizing pulse to $+20 \mathrm{mV}$ because of the strong inward rectification of $I_{K r}$.

\section{Ionic mechanisms of spontaneous action potentials}

The spontaneous activity of the cell was successfully reproduced as a result of the coordination of all the ion channels and transporters in the model. The action potential parameters are compared in Table 1. Both the maxi-
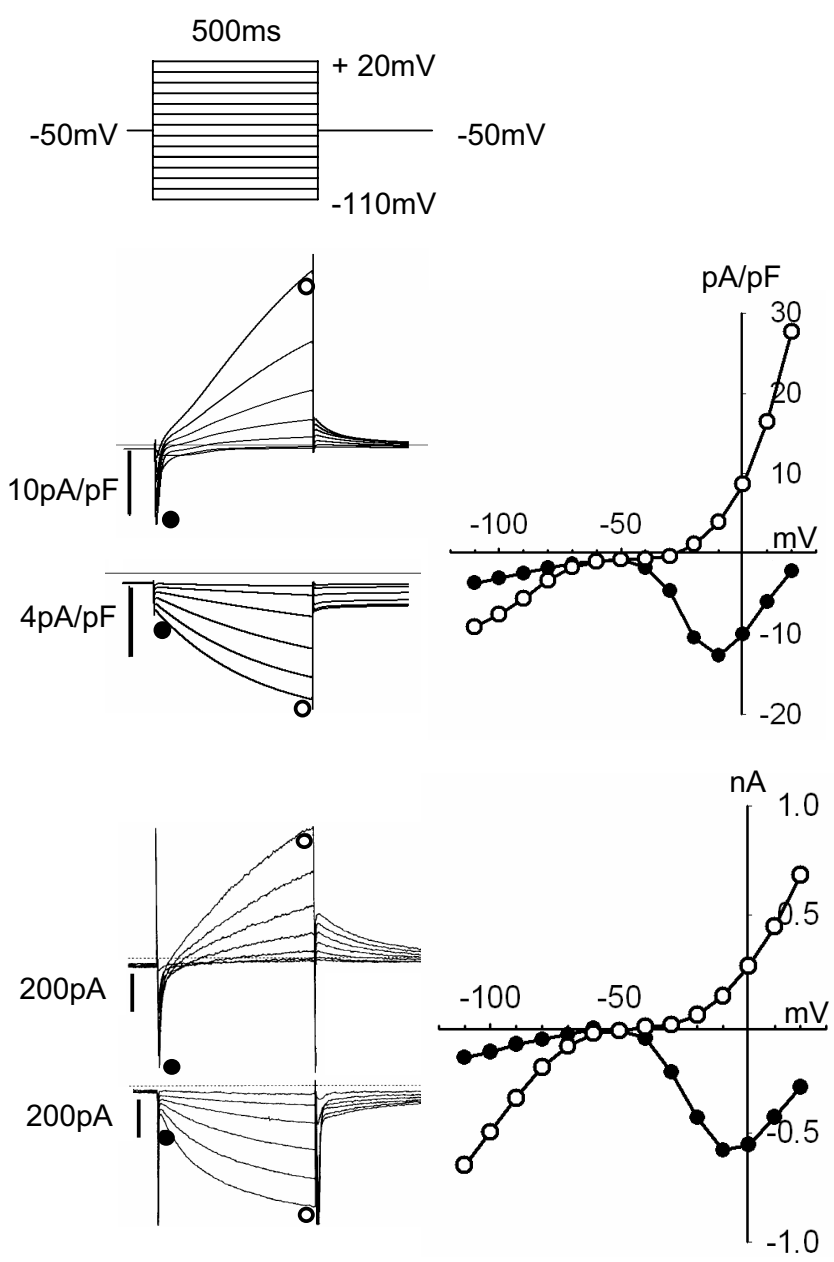

Fig. 6. Membrane currents in the guinea pig SAN model and in experiments. Membrane current traces induced by depolarizing (from -40 to $+20 \mathrm{mV}$, upper traces) and hyperpolarizing (from -60 to $-110 \mathrm{mV}$, lower traces) pulses (left panel) from a holding potential at $-50 \mathrm{mV}$ and the current-voltage relationship (right panel) from simulation (top) and from the experimental data of Guo et al. (1997) (bottom). The peak inward current on depolarization or the initial current level on hyperpolarization $(\bullet)$ and the late current levels measured near the end of $500 \mathrm{~ms}$ pulses $(\mathrm{O})$ were plotted against $V_{m}$.

mum diastolic potential and the overshoot are in good agreement with those in the experiments. The maximum rate of rise in the simulation is within the range of experimental data reported by Guo et al. (1997) [30] and Toyoda et al. (2005) [26], but slightly larger than that of Rigg et al. (2000) [31], and the spontaneous frequency agrees well with Rigg et al. (2000) [31]. To understand the mechanism underlying pacemaker depolarization, we adopted the "lead potential, $V_{L}$ " analysis introduced by Sarai et al. (2003) [2]. The lead potential is defined by the equivalent circuit shown in Fig. 7A, where $d V_{m} / d t$ is given as

$$
\frac{d V_{m}}{d t}=-\frac{G_{m} \cdot\left(V_{m}-V_{L}\right)}{C_{m}} .
$$

Both $V_{L}$ and $G_{m}$ vary automatically in the SAN model ac- 
Table 1. Action potential parameters of single guinea pig SANs. In the simulation, parameters were obtained in the steady state for control data and $30 \mathrm{~s}$ after the application of $0.01 \mu \mathrm{M}$ and $0.1 \mu \mathrm{M}$ ISO.

\begin{tabular}{|c|c|c|c|c|c|c|}
\hline Reference & & $\begin{array}{c}\text { Maximum } \\
\text { diastolic } \\
\text { potential }(\mathrm{mV})\end{array}$ & $\begin{array}{l}\text { Overshoot } \\
\quad(\mathrm{mV})\end{array}$ & $\begin{array}{l}\text { Total amplitude } \\
(\mathrm{mV})\end{array}$ & $\begin{array}{l}\text { Maximum rate of } \\
\text { rise }(\mathrm{V} / \mathrm{s})\end{array}$ & $\begin{array}{l}\text { Frequency } \\
\text { (/min) }\end{array}$ \\
\hline \multirow{2}{*}{$\begin{array}{l}\text { Rigg et al. } \\
(2000) \text { [31] }\end{array}$} & Control & $-57 \pm 2$ & $16 \pm 4$ & 73 & $1.5 \pm 0.4$ & $132 \pm 19$ \\
\hline & [ISO] $0.1 \mu \mathrm{M}$ & $-62 \pm 3$ & $27 \pm 4$ & 89 & $3.5 \pm 0.6$ & $284 \pm 14$ \\
\hline $\begin{array}{l}\text { Guo et al. } \\
\text { (1997) [30] }\end{array}$ & Control & $-58.7 \pm 3.8$ & $17.9 \pm 4.8$ & 76.6 & $3.6 \pm 1.3$ & $191 \pm 76.6$ \\
\hline $\begin{array}{l}\text { Toyoda et al. } \\
\text { (2005) [26] }\end{array}$ & Control & $-64.3^{*}$ & $17.5^{\star}$ & 81.8 & $7.0 \pm 1.2$ & $178 \pm 8$ \\
\hline \multirow[t]{2}{*}{$\begin{array}{l}\text { Matsuura et al. } \\
(2002)[13]\end{array}$} & Control & $-64.3 \pm 1.8^{*}$ & $22.5^{\star}$ & 86.8 & - & $205 \pm 11$ \\
\hline & Control & -64.81 & 12.93 & 77.74 & 4.33 & 131.9 \\
\hline \multirow[t]{2}{*}{ Simulation } & [ISO] $0.01 \mu \mathrm{M}$ & -65.5 & 13.69 & 79.19 & 5.117 & 159.9 \\
\hline & [ISO] $0.1 \mu \mathrm{M}$ & -66.12 & 15.04 & 81.16 & 7.29 & 177.6 \\
\hline
\end{tabular}

${ }^{\star}$ Data were corrected for a liquid junction potential of $5 \mathrm{mV}$ between the aspartate-rich pipette solution and the Tyrode solution. The results were expressed as the mean \pm SEM except for results obtained by Guo et al., which were expressed as the mean \pm SD.

cording to the time-dependent changes in membrane ionic conductance $\left(G_{X}\right)$ and the equilibrium potential $\left(E_{X}\right)$ for each ionic species $(\mathrm{X})$ :

$$
\begin{aligned}
& G_{m}=G_{K}+G_{N a}+G_{C a}+G_{C l}, \\
& V_{L}=\frac{G_{K} E_{K}+G_{N a} E_{N a}+G_{C a} E_{C a}+G_{C l} E_{C l}-I_{N a K}-I_{P M C A}}{G_{m}} .
\end{aligned}
$$

When $G_{K}, G_{N a}, G_{C a}$, and $G_{C l}$ were calculated from the total $\mathrm{K}^{+}, \mathrm{Na}^{+}, \mathrm{Ca}^{2+}$, and $\mathrm{Cl}^{-}$fluxes (Table $\mathrm{S} 4$ ), respective- ly, along the time course of the spontaneous action potential, $V_{L}$ changed as shown in the control panel in Fig. 7B ( $V_{L}$ in red and $V_{m}$ in gray). When $d V_{m} / d t$ is positive, $V_{L}$ is more positive than $V_{m}$, so that an inward current is generated and the membrane depolarizes, with the opposite effect of when $d V_{m} / d t$ is negative. $V_{L}$ crossed $V_{m}$ at all flexion points where $d V_{m} / d t$ is zero at the overshoot potential and the maximum diastolic potential.

To evaluate the contribution of individual currents to the slow diastolic depolarization by $V_{L}$ analysis, the gating parameter for a given current was fixed for $275 \mathrm{~ms}$ (un-

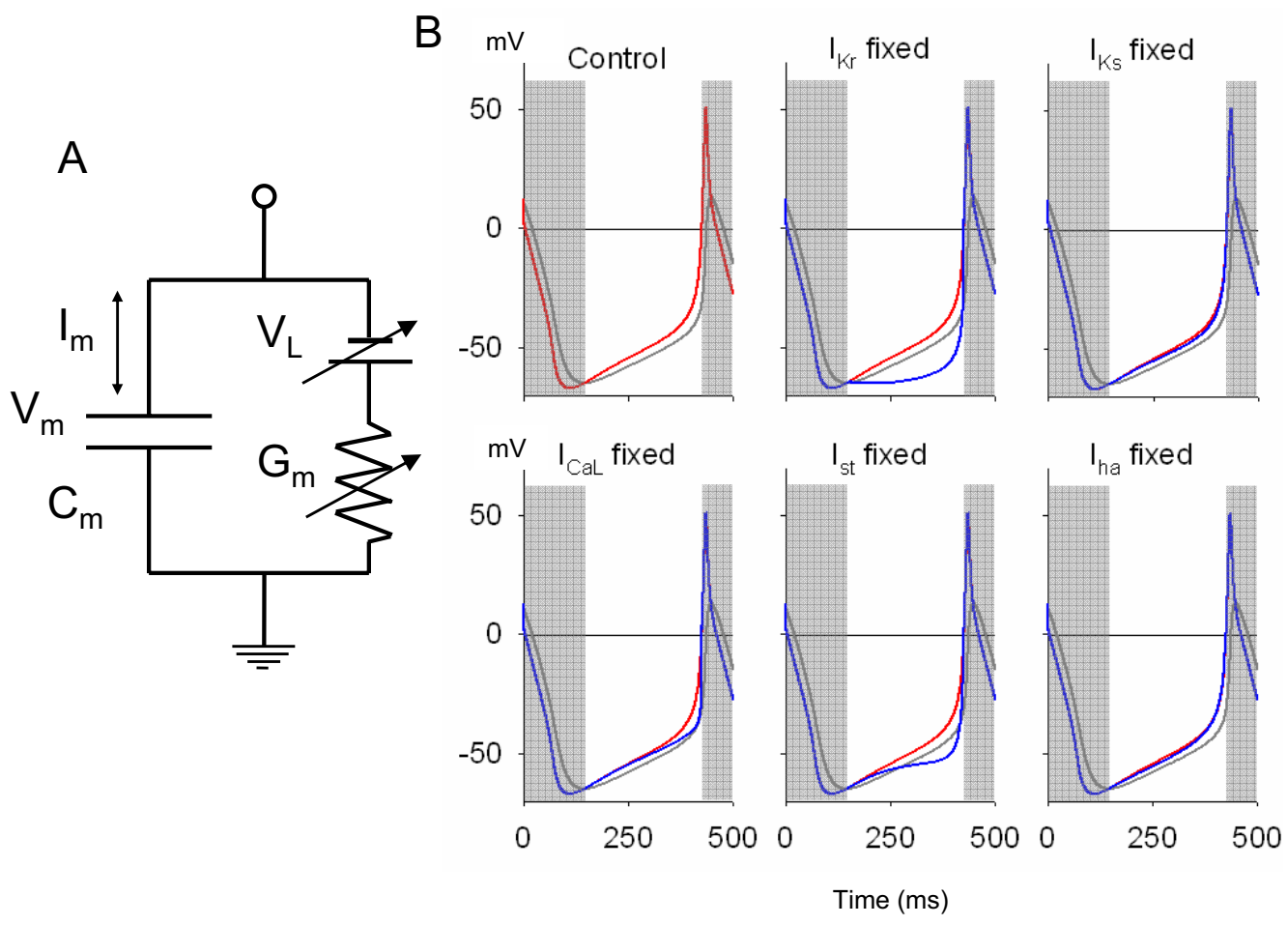

Fig. 7. The "lead potential, $V_{L}$ " and contribution of currents to slow diastolic depolarization. (A) The equivalent circuit for whole-cell electrophysiology. (B) $V_{L}$ (blue line) was calculated and superimposed on $V_{m}$ (gray line) and $V_{L}$ (red line) in control. Except in the control recording, for the calculation of $V_{L}$ the gating parameters of $I_{K r} I_{K s}, I_{C a L}$, $I_{s t}$, and $I_{h a}$ were fixed at values obtained at the maximum diastolic potential (150 $\mathrm{ms})$ and released after a period of $275 \mathrm{~ms}$ (unshaded). 
A

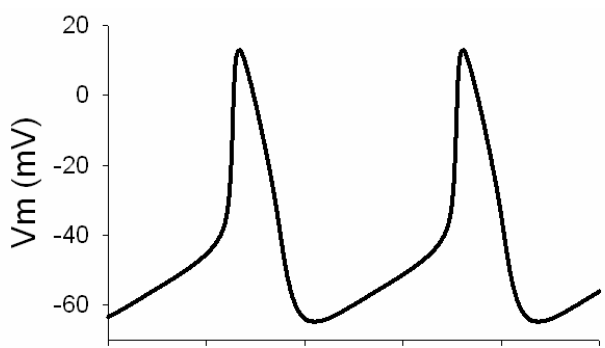

B

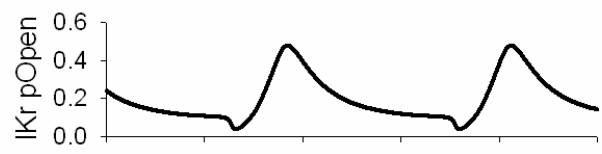

C

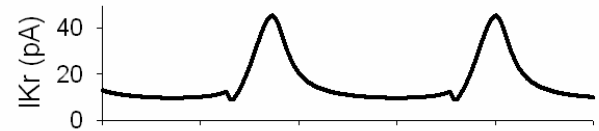

D

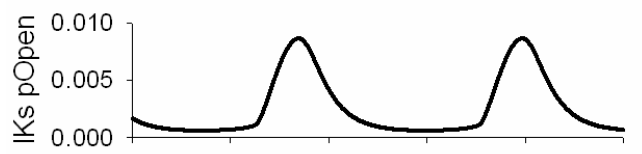

$\mathrm{E}$

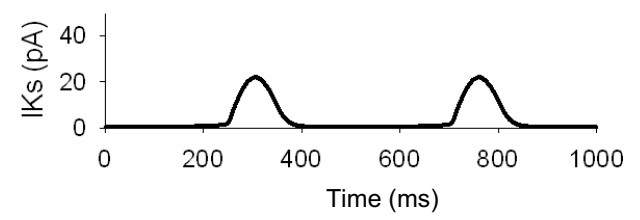

Fig. 8. Simulated channel opening probabilities for $I_{K r}$ and $I_{K s}$. (A) $V_{m}$. (B) Opening probability of $I_{K r}$ (C) Current amplitude of $I_{K r}$ (D) Opening probability of $I_{K_{s}}$ (E) Current amplitude of $I_{K s}$. Note the difference in scales between the probabilities for $I_{K r}$ and $I_{K s}$.

shaded period) at the value obtained at the maximum diastolic potential. Note that the calculation of $V_{L}$ (blue line) was independent from that of $V_{m}$ (gray line); thus the time course of $V_{m}$ is the same in all panels. When the gating parameter of $I_{K r}$ was fixed, $V_{L}$ became flat below $V_{m}$, indicating that $I_{K r}$ is mainly responsible for slow diastolic depolarization. In contrast, when the gating parameter of $I_{K s}$ was fixed, the time course of $V_{L}$ was only moderately modified if compared with the control $V_{L} . I_{C a L}$ played an important role in accelerating the last phase of slow diastolic depolarization, which was in agreement with its activation threshold at around $-40 \mathrm{mV}$. $I_{s t}$ played a crucial role in determining the depolarizing rate in the latter half of slow diastolic depolarization, as is evident in the panel for $I_{s t}$. Fixing $I_{h a}$ gating had almost no effect on $V_{L}$. These findings are in good agreement with a previous study in the "rabbit" SAN model [2].

To gain a deeper insight into the contribution of $I_{K s}$ to the rate of slow diastolic depolarization in comparison to $I_{K r}$, open probabilities and amplitudes of $I_{K s}$ and $I_{K r}$ were compared during slow diastolic depolarization (Fig. 8). The driving force for outward $\mathrm{K}^{+}$flux increased in a timedependent manner, but the open probability of $I_{K r}$ de- creased gradually from 0.46 to 0.10 (Fig. 8B); thus the current amplitudes of $I_{K r}$ remained fairly constant in the late phase of pacemaker depolarization (Fig. 8C). As expected from the deactivation time course of $I_{K S}$ in the voltage clamp experiment (Fig. 5), the open probability of $I_{K s}$ also decreased during diastolic depolarization (Fig. 8D). However, the amplitude of $I_{K s}$ was very small after the time of the maximum diastolic potential. This was because the open probability of $I_{K s}$ during the action potential was only 0.007 at the maximum, which was $1 / 58.8$ of $I_{K r}$ because of its slow activation kinetics. Furthermore, the reversal potential of $I_{K s}$ was less negative than that of $I_{K r}$, giving a smaller electrochemical driving force for $I_{K s}$ during diastole. Thus $I_{K s}$ could not contribute to the decay in the whole cell $\mathrm{K}^{+}$conductance during slow diastolic depolarization (Fig. 8E).

\section{Time course of responses to $\beta 1$-adrenergic stimulation}

The time course of the $\beta 1$-adrenergic effect is one of the critical factors in controlling arterial blood pressure or in evaluating autonomic regulation using the R-R interval variability. Here the time course of firing frequency of SANs was examined in terms of underlying reaction cascade in the model (Fig. 9).

The concentration of cAMP increased exponentially within the initial $20 \mathrm{~s}$ after the onset of ISO application, as shown in the top panel of Fig. 9A, and its saturation level was determined by the phosphodiesterase (PDE) activity. The fraction of the free catalytic subunit of PKA showed almost the same time course as that of cAMP (Fig. 9A, middle panel). Approximately $13 \%$ of the activated catalytic subunit was inactivated by the binding of protein kinase inhibitor (PKI) at $30 \mathrm{~s}$ after the application of 0.01 $\mu \mathrm{M}$ ISO. The increase of firing frequency saturated much earlier than those of cAMP or PKA activation after ISO application (Fig. 9A, bottom panel). This dissociation of the time course in firing frequency from that in cAMP or PKA is due to the nonlinear relationship between the channel activation and the firing frequency; however, the details of the mechanism are currently unclear. We were only able to test the secondary effect of a modified intracellular $\mathrm{Na}^{+}$concentration $\left(\left[\mathrm{Na}^{+}\right]_{\mathrm{i}}\right)$, which increased almost linearly to $5.13 \mathrm{mM}$, from 4.45 , within the initial $30 \mathrm{~s}$ of ISO application. Indeed, the outward $I_{\mathrm{NaK}}$, modulated by activated PKA, was gradually enlarged by the increase in $\left[\mathrm{Na}^{+}\right]_{\mathrm{i}}$ (Fig. 9B, top panel). When the amplitude of $I_{\mathrm{NaK}}$ was temporarily decreased to the initial level (Fig. 9B, middle panel) by arbitrarily decreasing its magnitude factor, the firing frequency was increased. The enhancement of $I_{\mathrm{NaK}}$ by increasing the concentration of intracellular $\mathrm{Na}^{+}$ was one of the mechanisms responsible for the early saturation in the acceleration of firing frequency.

The relationship between the increase in firing frequency and ISO concentration is shown in Fig. 9C. The firing 


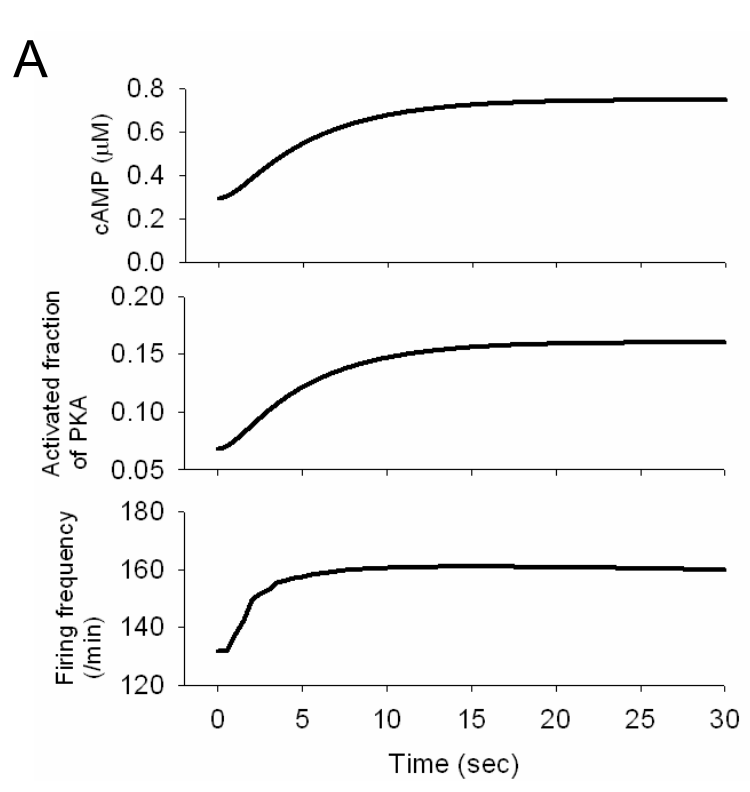

B
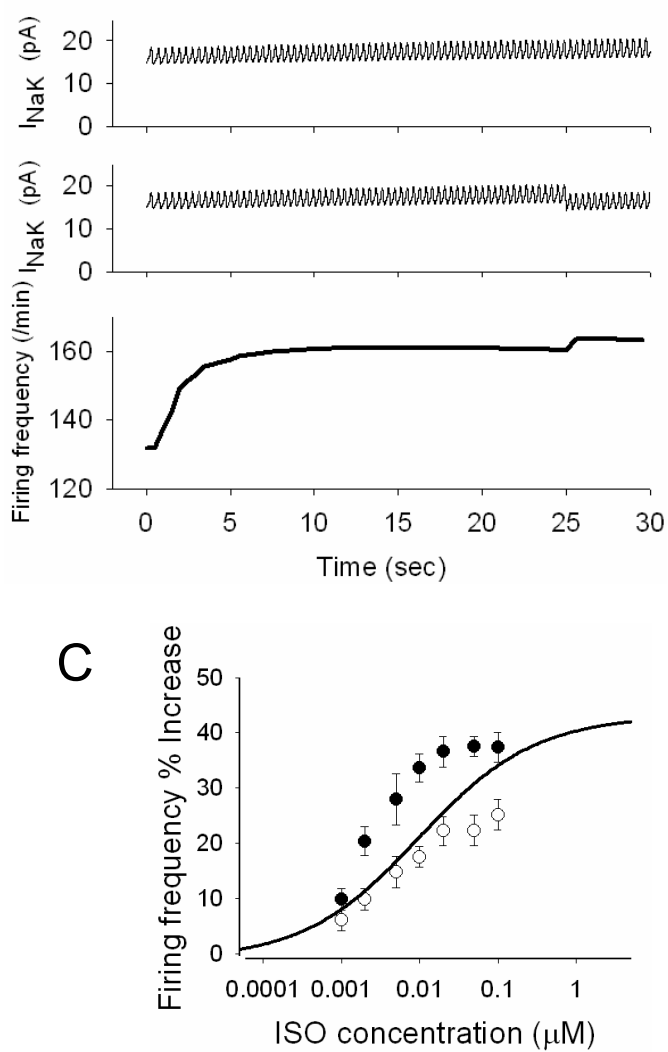

Fig. 9. Simulation of $\beta 1$-adrenergic action on increase in cAMP, activation of PKA, and increase in firing frequency. (A) Time courses for the increase in CAMP and the activation of PKA by $0.01 \mu \mathrm{M}$ ISO are shown in the top and middle panels, respectively. A simultaneous recording for the change in firing frequency is shown in the bottom panel. (B) The time course of enhancement of $I_{\mathrm{NaK}}$ after the application of $0.01 \mu \mathrm{M}$ ISO is shown in the top panel. In the middle panel, the amplitude of $I_{\mathrm{NaK}}$ was decreased to the control current at time zero by re-

ducing the number of $\mathrm{Na}^{+} / \mathrm{K}^{+}$pumps at $25 \mathrm{~s}$ in silico. The time course of the firing frequency with the reduction of the amplitude of $I_{\mathrm{NaK}}$ is shown in the bottom panel. (C) ISO dose-dependent increase in firing frequency. Data were obtained $30 \mathrm{~s}$ after ISO application. Symbols with error bars indicate experimental data (mean \pm SEM) in a guinea pig multicellular preparation by Rigg et al. (2000) with $(\mathrm{O})$ and without $(\bullet) 2 \mu \mathrm{M}$ ryanodine [31].

frequency was measured $30 \mathrm{~s}$ after the application of ISO, which increased the frequency by $41.5 \%$ from the control rate at the maximum dose $(10 \mu \mathrm{M})$ of ISO. Experimental data from Rigg et al. (2000) [31] were superimposed on the simulation result. The curve obtained from simulation $\left(\mathrm{n}_{\mathrm{H}}=0.586, \mathrm{~K}_{\mathrm{D}}=0.0098 \mu \mathrm{M}\right)$ almost coincided with the experimental result in the presence of $2 \mu \mathrm{M}$ ryanodine $(\mathrm{O})$ in the low concentration range below $0.01 \mu \mathrm{M}$, but the slope was shallower than that obtained without ryanodine $(\bullet)$. The approximate half-maximal dose for ISO, 0.01 $\mu \mathrm{M}$, was used in further analyses in this study.

The parameters of action potentials in simulations in ISO $(0.01$ and $0.1 \mu \mathrm{M})$ are compared in the Table 1 with experimental data $(0.1 \mu \mathrm{M})$ in isolated guinea pig SANs from Rigg et al. [31]. The maximum diastolic potential, overshoot, total amplitude, maximum rate of rise, and frequency increased in both the simulation and the experiment in the presence of ISO. The increase in firing frequency in the simulation was smaller than that in the experiment.

In the current model, $J_{N K C C l}$ and $I_{C l b}$ are not modified by $\beta 1$-adrenergic stimulation. However, $\left[\mathrm{Cl}^{-}\right]_{\mathrm{i}}$ increased due to changes in $I_{C l b}$, which is dependent on $V_{m}$, from a control level of $30.04 \mathrm{mM}$ to $30.06 \mathrm{mM}$ after the application of ISO for $2 \mathrm{~h}$. Because the change in $\left[\mathrm{Cl}^{-}\right]_{\mathrm{i}}$ was small, we concluded that the change in the cell volume was negligibly small.

\section{Ionic mechanisms of spontaneous action potential under $\beta 1$-adrenergic stimulation}

$V_{m}$ and currents obtained in control (black line) and $30 \mathrm{~s}$ after $0.01 \mu \mathrm{M}$ ISO application (red line) are superimposed individually at the time point of the maximum rate of rise in Fig. 10. The slope of slow diastolic depolarization was significantly increased by ISO application to $0.126 \mathrm{mV} / \mathrm{ms}$, from 0.087 , when measured over the linear portion of the diastolic depolarization. This increase in the depolarizing rate $(0.039 \mathrm{mV} / \mathrm{ms})$ can decrease the duration taken for $\sim 25$ $\mathrm{mV}$ depolarization from the maximum diastolic potential $(-65 \mathrm{mV})$ to the takeoff potential of the action potential 


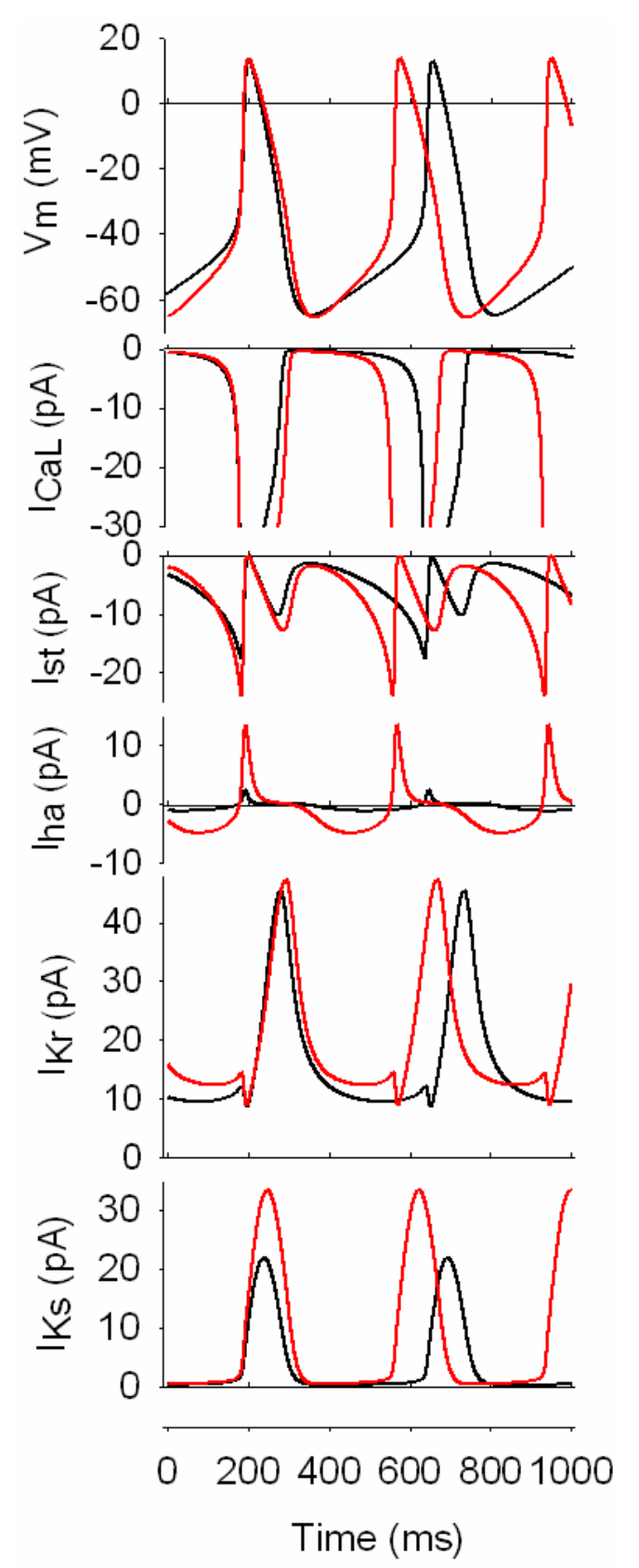

Fig. 10. Comparison of $V_{m}$ and ionic currents $\left(I_{C a L}, I_{s t}, I_{h a}, I_{K p}\right.$ and $I_{K s}$ ) before (black lines) and $30 \mathrm{~s}$ after the application of $0.01 \mu \mathrm{M}$ ISO (red lines). The maximum rates of rise of the initial action potential are superimposed. The peak of the $I_{C a L}$ is off the scale.

$(-40 \mathrm{mV})$ by $88 \mathrm{~ms}$. The negative shift of $I_{\text {CaL }}$ activation $\left(v_{\text {shift }}=1.7 \mathrm{mV}\right.$ with $0.378 \mu \mathrm{M}$ catalytic subunit of PKA) is marginal $(1.7 / 25=6.8 \%)$ if compared with the $25 \mathrm{mV}$ magnitude of the diastolic depolarization. Thus we conclude that the increase in the slope of diastolic depolarization is mainly responsible for the positive chronotropy. A prolongation of the action potential by about $15.4 \mathrm{~ms}$ partially compromised the positive chronotropic effect of the increased rate of diastolic depolarization.
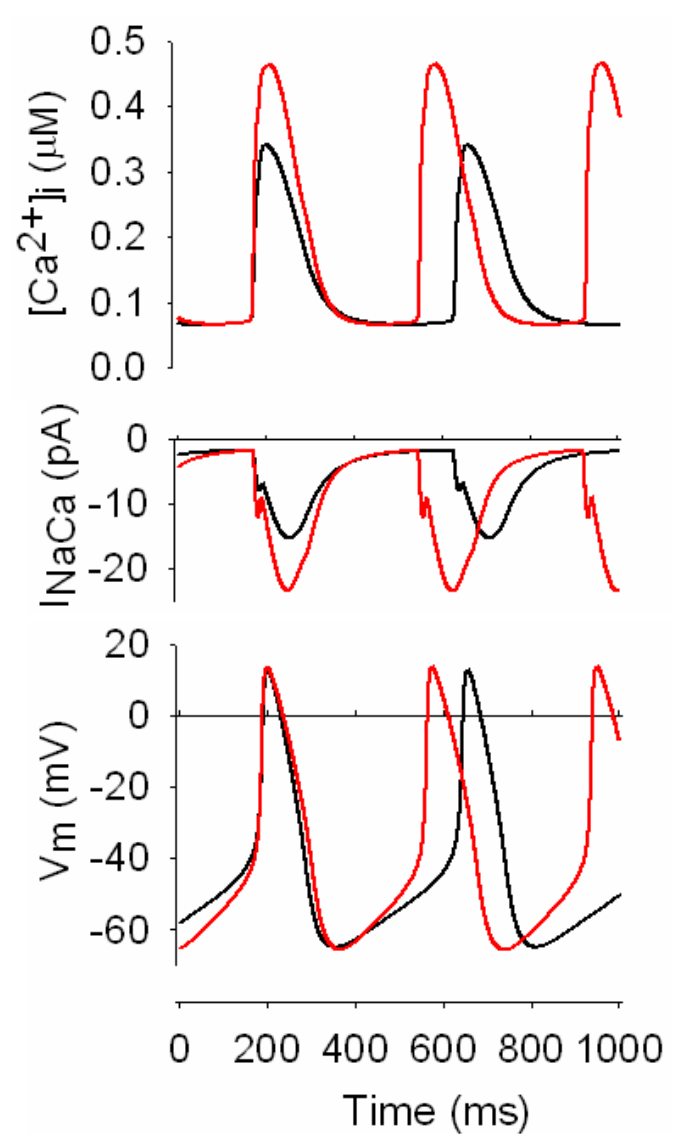

Fig. 11. Modulation of $I_{\mathrm{NaCa}}$ by $\beta 1$-adrenergic stimulation. Intracellular $\mathrm{Ca}^{2+}$ concentration, $I_{\mathrm{NaCa}}$, and $V_{m}$ are shown in the top, middle, and bottom panels, respectively. The traces were recorded for control conditions (black lines) and $30 \mathrm{~s}$ after the application of $0.01 \mu \mathrm{M}$ ISO (red lines).

The increase in the rate of diastolic depolarization is due to increases in both $I_{s t}$ and $I_{h a}$. If measured over the period from the maximum diastolic potential to the takeoff potential, the ratio of the increase of $I_{s t} / I_{h a}$ measured by the time integral of the increase of each current during slow diastolic depolarization was 1.19 , indicating almost equal contributions of these currents to the positive chronotropy.

The increase in the outward $I_{K r}$ during diastole is secondarily caused by the positive shift of $V_{m}$. On the other hand, the amplitude of $I_{K S}$ increased by up to $150 \%$ at the peak directly by the PKA catalytic subunit and activation of the $\mathrm{Ca}^{2+}$-dependent gate. The current amplitude of $I_{K s}$ was still negligibly small during diastolic depolarization after $\beta 1$-adrenergic stimulation.

\section{Increase in $I_{\mathrm{NaCa}}$ and positive chronotropy during $\beta 1$-adrenergic stimulation}

The increase in the amplitude of $I_{C a L}$ by $\beta 1$-adrenergic stimulation increased the $\mathrm{Ca}^{2+}$ content of the cell, especially within the SR, which then increased the magnitude of the $\mathrm{Ca}^{2+}$ transient by $56 \%$ at the peak, thereby increas- 


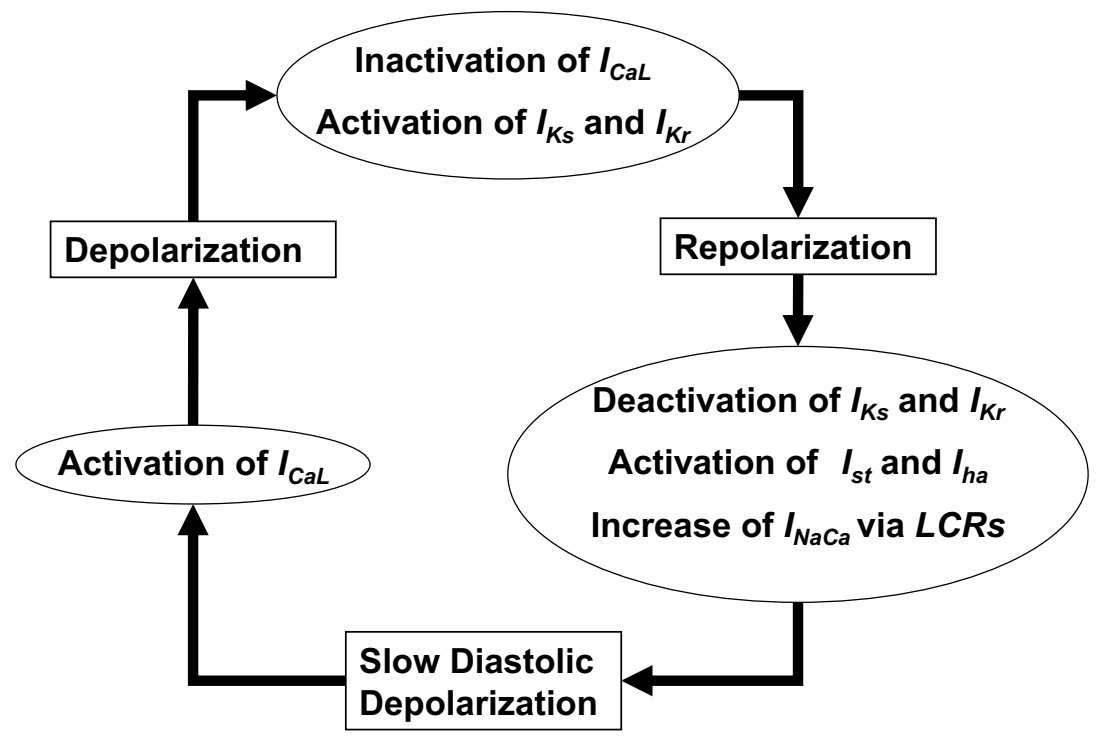

Fig. 12. Sequential events underlying the spontaneous action potential. LCR: Local subsarcolemmal ryanodine receptor-mediated $\mathrm{Ca}^{2+}$ release. ing the magnitude of $I_{\mathrm{NaCa}}$ during the $\mathrm{Ca}^{2+}$ transient. However, because of the PKA-dependent activation of $\mathrm{Ca}^{2+}$ uptake by SERCA, the decay of the $\mathrm{Ca}^{2+}$ transient accelerated during $\beta 1$-adrenergic stimulation, so that $\left[\mathrm{Ca}^{2+}\right]_{\mathrm{i}}$ and therefore the magnitude of inward $I_{\mathrm{NaCa}}$ were almost superimposable with control data during diastolic depolarization (Fig. 11, middle panel). Thus the above modulation of $I_{\mathrm{NaCa}}$ does not contribute to the positive chronotropy in the model. On the contrary, the increase in $I_{\mathrm{NaCa}}$ during the action potential hampered the positive chronotropic effect of $\beta 1$-adrenergic stimulation by prolonging the action potential duration. These conclusions differ from those in Kurata et al. (2002) [32] and Maltsev et al. (2004) [33] and will be discussed in the next section.

\section{DISCUSSION}

\section{$I_{K s}$ and $I_{K r}$ in the guinea pig SAN cell model}

$I_{K S}$ has recently been suggested to be a large component of $I_{K}$ in guinea pig SANs $[13,14]$, and therefore we investigated the contribution of $I_{K S}$ to slow diastolic depolarization by simulation. This analysis showed that the decay of $\mathrm{K}^{+}$conductance by the deactivation of $I_{K r}$, but not by $I_{K s}$, only influenced the lead potential, $V_{L}$, and played a major role in determining pacemaker depolarization in guinea pig SANs, as also found in other mammalian species, including rabbit $[11,12,19,34]$. We clearly showed the slight possibility of involvement of $I_{K s}$ in slow diastolic depolarization because the activation of $I_{K s}$ during the preceding action potential was negligibly small. On the other hand, the activation of $I_{K r}$ was rapid, and the amplitude of $I_{K r}$ was larger than $I_{K s}$, during the repolarizing phase of action potential (Figs. 8 and 10). Even the amplitude of $I_{K r}$, measured as the E-4031 sensitive component of the tail current in the voltage clamp experiment, was only half (approximately $51 \%$ with $100 \mathrm{~ms}$ test pulse) that of $I_{K s}$ in Fig. 2 in Matsuura et al. (2002) [13]. Our simulation sug- gested that the increase of $I_{K s}$ is useful in inhibiting the prolongation of the action potential by counterbalancing the increase in $I_{\mathrm{CaL}}$ and $I_{\mathrm{NaCa}}$ during $\beta 1$-adrenergic stimulation. We assumed that $I_{K r}$ was not modulated by $\beta 1$ adrenergic stimulation in our model, but it has been reported that the deactivation rate of $I_{K}$ is accelerated by ISO in rabbit SANs. The authors suggested that the rate of slow diastolic depolarization would be accelerated by this mechanism during $\beta 1$-adrenergic stimulation [35]. However, it was difficult to reproduce simultaneous negative shifts in the I-V relationship and an increase in decay rate because negative shifts in the voltage dependency of activation were usually accompanied by a decrease in deactivation rate in the conventional voltage-dependent gate model. Therefore this mechanism was not included in our model.

\section{Intracellular $\mathrm{Ca}^{2+}$ concentration and pacemaker activity}

It is still a matter of debate whether intracellular $\mathrm{Ca}^{2+}$ dynamics affect pacemaker activity $[9,10,36]$. The mechanism in which the inward $I_{\mathrm{NaCa}}$ was enhanced by the time-dependent local intracellular $\mathrm{Ca}^{2+}$ concentration and accelerated pacemaker depolarization has been reproduced only in the model developed by Kurata et al. (2002) [32]. In this model, it was assumed that the subsarcolemmal domain of $1 \%$ of the cell volume increased the $\mathrm{Ca}^{2+}$ concentration-dependent enhancement of $I_{\mathrm{NaCa}}$ during the last $60 \mathrm{~ms}$ of slow diastolic depolarization, and that activated $I_{C a T}$ increased the local subsarcolemmal $\mathrm{Ca}^{2+}$ concentration in addition to $\mathrm{SR} \mathrm{Ca}^{2+}$ release during slow diastolic depolarization. However, without the effect of the subsarcolemmal domain (as in our model), $\mathrm{Ca}^{2+}$ released from the SR diffuses to the cytosol instantaneously and does not enhance $I_{\mathrm{NaCa}}$. Similarly, the inclusion of diastolic spontaneous local $\mathrm{Ca}^{2+}$ release from the SR, as measured by Bogdanov et al. (2001) [37], in a model includ- 
ing the subsarcolemmal space increases the rate of slow diastolic depolarization by activating $I_{\mathrm{NaCa}}$ [33]. To assess the validity of different models, we need to determine experimentally if the subsarcolemmal $\mathrm{Ca}^{2+}$ concentration is changed when EGTA is applied to inhibit the global (myoplasmic) $\mathrm{Ca}^{2+}$ transient. This is because most of the spontaneous action potentials have been recorded using the ruptured patch clamp mode with EGTA in the pipette solution. The amplitude of $I_{C a T}$ is still uncertain in guinea pig SANs, and further experiments are needed. It is also important to consider variability in the distributions of ionic channels [36] according to the location and size of the cells [38] when the contribution of the SR to pacemaker activity is being discussed [39].

\section{Spontaneous activity and mechanisms of positive chronotropy during $\beta 1$-adrenergic stimulation in SANs}

The positive chronotropic effect of $\beta 1$-adrenergic stimulation is summarized in Fig. 12, using the scheme of sequential events during the spontaneous action potential. The negative shift of $I_{C a L}$ activation, which supports the initial rising phase and the overshoot of the action potential [40], was only supplemental to the $\beta 1$-adrenergic chronotropy at moderate agonist concentrations. The increase in the $I_{\mathrm{CaL}}$ magnitude prolongs the duration of action potentials and thereby decreases the firing frequency, as suggested by Sarai et al. (2003) [2]. In turn, the increased intracellular $\mathrm{Ca}^{2+}$ transient under $\beta 1$-adrenergic stimulation partly compensated for the increase in the action potential duration by inactivating $I_{C a L}$ and activating $I_{K s}$. The increase in $I_{h a}$ and $I_{s t}$ contributed equally to accelerating slow diastolic depolarization. The contribution of $I_{\mathrm{NaCa}}$ to modifying slow diastolic depolarization was almost negligible in our model, even in the presence of $\beta 1$ adrenergic agonist. However, such currents might play a crucial role in increasing the rate of depolarization only if $I_{\mathrm{NaCa}}$ is strongly coupled with SR $\mathrm{Ca}^{2+}$ release by assuming a very limited subsarcolemmal space, as in the model of Kurata et al. (2002) [32] and in the modified version of this model in Maltsev et al. (2004) [33].

The authors thank Professor T. Powell, Associate Professor T. Mitsuiye, and members of the Cell/Biodynamics Simulation Project, Kyoto University, for their suggestions. This work was supported by the Leading Project for Biosimulation from the Ministry of Education, Culture, Sports, Science and Technology of Japan.

\section{REFERENCES}

1. Matsuoka S, Sarai N, Kuratomi S, Ono K, Noma A. Role of individual ionic current systems in ventricular cells hypothesized by a model study. Jpn J Physiol. 2003;53:105-23.

2. Sarai N, Matsuoka S, Kuratomi S, Ono K, Noma A. Role of individual ionic current systems in the SA node hypothesized by a model study. Jpn J Physiol. 2003;53:125-34.

3. Matsuoka S, Sarai N, Jo H, Noma A. Simulation of ATP metabolism in cardiac excitation-contraction coupling. Prog Biophys Mol Biol. 2004;85:279-99.
4. Terashima K, Takeuchi A, Sarai N, Matsuoka S, Shim EB, Leem CH, Noma A. Modelling $\mathrm{Cl}^{-}$homeostasis and volume regulation of the cardiac cell. Philos Transact A Math Phys Eng Sci. 2006;364:1245-65.

5. Takeuchi A, Tatsumi S, Sarai N, Terashima K, Matsuoka S, Noma A. Ionic mechanisms of cardiac cell swelling induced by blocking $\mathrm{Na}^{+} / \mathrm{K}^{+}$pump as revealed by experiments and simulation. J Gen Physiol. 2006;128:495-507.

6. Kuzumoto M, Takeuchi A, Nakai H, Oka C, Noma A, Matsuoka S. Simulation analysis of intracellular $\mathrm{Na}^{+}$and $\mathrm{Cl}^{-}$homeostasis during beta1-adrenergic stimulation of cardiac myocyte. Prog Biophys Mol Biol. 2007; in press.

7. Rigg $L$ Terrar DA. Possible role of calcium release from the sarcoplasmic reticulum in pacemaking in guinea-pig sino-atrial node. Exp Physiol. 1996;81:877-80.

8. Li J, Qu J, Nathan RD. Ionic basis of ryanodine's negative chronotropic effect on pacemaker cells isolated from the sinoatrial node. Am J Physiol. 1997;273:H2481-9.

9. Honjo H, Inada S, Lancaster MK, Yamamoto M, Niwa R, Jones SA, Shibata N, Mitsui K, Horiuchi T, Kamiya K, Kodama I, Boyett MR. Sarcoplasmic reticulum $\mathrm{Ca}^{2+}$ release is not a dominating factor in sinoatrial node pacemaker activity. Circ Res. 2003;92:e41-4.

10. Lakatta EG, Maltsev VA, Bogdanov KY, Stern MD, Vinogradova TM. Cyclic variation of intracellular calcium: a critical factor for cardiac pacemaker cell dominance. Circ Res. 2003;92:e45-50.

11. Irisawa H, Brown HF, Giles W. Cardiac pacemaking in the sinoatrial node. Physiol Rev. 1993;73:197-227.

12. Noma A. Ionic mechanisms of the cardiac pacemaker potential. Jpn Heart J. 1996;37:673-82.

13. Matsuura H, Ehara T, Ding WG, Omatsu-Kanbe M, Isono T. Rapidly and slowly activating components of delayed rectifier $\mathrm{K}^{+}$current in guinea-pig sino-atrial node pacemaker cells. J Physiol. 2002;540:815-30.

14. Anumonwo JM, Freeman LC, Kwok WM, Kass RS. Delayed rectification in single cells isolated from guinea pig sinoatrial node. Am J Physiol. 1992;262:H921-5.

15. Korzeniewski B Zoladz JA. A model of oxidative phosphorylation in mammalian skeletal muscle. Biophys Chem. 2001;92:17-34.

16. Nichols CG Lederer WJ. Adenosine triphosphate-sensitive potassium channels in the cardiovascular system. Am J Physiol. 1991;261:H1675-86.

17. Jo H, Noma A, Matsuoka S. Calcium-mediated coupling between mitochondrial substrate dehydrogenation and cardiac workload in single guinea-pig ventricular myocytes. J Mol Cell Cardiol. 2006;40:394-404.

18. Takano M Noma A. Distribution of the isoprenaline-induced chloride current in rabbit heart. Pflugers Arch. 1992;420:223-6.

19. Ito $\mathrm{H}$ Ono K. A rapidly activating delayed rectifier $\mathrm{K}^{+}$channel in rabbit sinoatrial node cells. Am J Physiol. 1995;269:H443-52.

20. Ono $\mathrm{K}$ Ito $\mathrm{H}$. Role of rapidly activating delayed rectifier $\mathrm{K}^{+}$current in sinoatrial node pacemaker activity. Am J Physiol. 1995;269:H453-62.

21. Sarai N, Matsuoka S, Noma A. simBio: a Java package for the development of detailed cell models. Prog Biophys Mol Biol. 2006; 90:

22. Kameyama M, Hofmann F, Trautwein W. On the mechanism of beta-adrenergic regulation of the $\mathrm{Ca}$ channel in the guinea-pig heart. Pflugers Arch. 1985; 405:285-93.

23. Zaza A, Robinson RB, DiFrancesco D. Basal responses of the L-type $\mathrm{Ca}^{2+}$ and hyperpolarization-activated currents to autonomic agonists in the rabbit sinoatrial node. J Physiol. 1996; 491 ( Pt 2): 347-55.

24. Ke Y, Lei M, Collins TP, Rakovic S, Mattick PA, Yamasaki M, Brodie MS, Terrar DA, Solaro RJ. Regulation of L-type calcium channel and delayed rectifier potassium channel activity by 121 -activated kinase-1 in guinea pig sinoatrial node pacemaker cells. Circ Res. 2007;100:1317-27.

25. McDonald TF, Pelzer S, Trautwein W, Pelzer DJ. Regulation and modulation of calcium channels in cardiac, skeletal, and smooth muscle cells. Physiol Rev. 1994;74:365-507.

26. Toyoda F, Ding WG, Matsuura H. Responses of the sustained inward current to autonomic agonists in guinea-pig sino-atrial node pacemaker cells. $\mathrm{Br} \mathrm{J}$ Pharmacol. 2005; 144:660-8.

27. Bucchi A, Baruscotti M, Robinson RB, DiFrancesco D. I(f)-dependent modulation of pacemaker rate mediated by CAMP in the presence of ryanodine in rabbit sino-atrial node cells. J Mol Cell Cardiol. 2003;35:905-13.

28. Hagiwara N Irisawa H. Modulation by intracellular $\mathrm{Ca}^{2+}$ of the hyperpolarizationactivated inward current in rabbit single sino-atrial node cells. J Physiol. 1989;409:121-41.

29. Ding WG, Toyoda F, Matsuura H. Blocking action of chromanol 293B on the slow component of delayed rectifier $\mathrm{K}^{+}$current in guinea-pig sino-atrial node cells. $\mathrm{Br}$ J Pharmacol. 2002;137:253-62.

30. Guo J, Mitsuiye T, Noma A. The sustained inward current in sino-atrial node cells 


\section{$\beta 1$-Adrenergic Positive Chronotropy in a SAN Model}

of guinea-pig heart. Pflugers Arch. 1997;433:390-6.

31. Rigg L, Heath BM, Cui Y, Terrar DA. Localisation and functional significance of ryanodine receptors during beta-adrenoceptor stimulation in the guinea-pig sinoatrial node. Cardiovasc Res. 2000;48:254-64.

32. Kurata Y, Hisatome I, Imanishi S, Shibamoto T. Dynamical description of sinoatrial node pacemaking: improved mathematical model for primary pacemaker cell. Am J Physiol Heart Circ Physiol. 2002;283:H2074-101.

33. Maltsev VA, Vinogradova TM, Bogdanov KY, Lakatta EG, Stern MD. Diastolic calcium release controls the beating rate of rabbit sinoatrial node cells: numerical modeling of the coupling process. Biophys J. 2004;86:2596-605.

34. Verheijck EE, van Ginneken AC, Bourier J, Bouman LN. Effects of delayed rectifier current blockade by E-4031 on impulse generation in single sinoatrial nodal myocytes of the rabbit. Circ Res. 1995;76:607-15.

35. Lei M, Brown HF, Terrar DA. Modulation of delayed rectifier potassium current, iK, by isoprenaline in rabbit isolated pacemaker cells. Exp Physiol. 2000;85:27-35.

36. Musa H, Lei M, Honjo H, Jones SA, Dobrzynski H, Lancaster MK, Takagishi Y, Henderson Z, Kodama I, Boyett MR. Heterogeneous expression of $\mathrm{Ca}^{2+}$ handling proteins in rabbit sinoatrial node. J Histochem Cytochem. 2002;50:31124.

37. Bogdanov KY, Vinogradova TM, Lakatta EG. Sinoatrial nodal cell ryanodine receptor and $\mathrm{Na}^{+}-\mathrm{Ca}^{2+}$ exchanger: molecular partners in pacemaker regulation. Circ Res. 2001;88:1254-8.

38. Boyett MR, Honjo H, Kodama I, Lancaster MK, Lei M, Musa H, Zhang H. The sinoatrial node: cell size does matter. Circ Res. 2007;101:e81-2.

39. Boyett MR, Honjo H, Kodama I. The sinoatrial node, a heterogeneous pacemaker structure. Cardiovasc Res. 2000;47:658-87.

40. Noma A Irisawa $\mathrm{H}$. Effects of calcium ion on the rising phase of the action potential in rabbit sinoatrial node cells. Jpn J Physiol. 1976;26:93-9. 